\title{
Fuel Gas Production from Biomass Sources by Radio Frequency In-Liquid Plasma Method
}

\author{
Ismail Rahim ${ }^{1,2 *}$, Shinfuku Nomura1*, Shinobu Mukasa1, Hiromichi Toyota1, \\ Katsunori Kawanishi' ${ }^{1}$, Yoshihiko Makiura ${ }^{3}$, Kazuhiko Kogoh ${ }^{3}$, \\ Kunihiro Ohshima ${ }^{3}$, Susumu Katsuen ${ }^{3}$ \\ ${ }^{1}$ Department of Engineering for Production and Environment, Graduate School of Science and Engineering, \\ Ehime University, Ehime, Japan \\ ${ }^{2}$ Department of Automotive Engineering Education, State University of Makassar, Makassar, Indonesia \\ ${ }^{3}$ KURABO Industries Ltd., Neyagawa, Japan \\ Email: ${ }^{*}$ ismail rahim@unm.ac.id, ${ }^{*}$ nomura.shinfuku.mg@ehime-u.ac.jp
}

Received 15 June 2015; accepted 4 August 2015; published 7 August 2015

Copyright (C) 2015 by authors and Scientific Research Publishing Inc.

This work is licensed under the Creative Commons Attribution International License (CC BY).

http://creativecommons.org/licenses/by/4.0/

c) (i) Open Access

\begin{abstract}
Cellulose is a kind of saccharide that is the main component in cell walls of plants and therefore is the organic compound that exists in the largest amount in nature. The purpose of this experiment is to convert cellulose to a fuel. Radio frequency (RF) in-liquid plasma is generated in a cellulose distributed solution and a glucose solution, and the generation gas rate is measured. While hydrogen is the main gas generated by the plasma breakdown, carbon monoxide, carbon dioxide, and low-grade flammable gases are also produced. In the glucose water solution or the glucose distributed solution, the solution itself evaporates and decomposes inside the plasma but since the saccharides are non-volatile, they cannot penetrate into the plasma and are not decomposition. However, when the cellulose is at concentrations of $30 \mathrm{wt} \%$ or more, it becomes granular and can directly enter the plasma as a solid, where the plasma decomposes the cellulose itself, significantly increasing the amount of gas generated. In addition, the spectrometry of the plasma emission shows the solution after the creation of plasma has the ability to absorb ultraviolet light.
\end{abstract}

\section{Keywords}

In-Liquid Plasma, Radio Frequency Plasma, Saccharide, Hydrogen, Decomposition

\footnotetext{
${ }^{*}$ Corresponding author.
}

How to cite this paper: Rahim, I., Nomura, S., Mukasa, S., Toyota, H., Kawanishi, K., Makiura, Y., Kogoh, K., Ohshima, K. and Katsuen, S. (2015) Fuel Gas Production from Biomass Sources by Radio Frequency In-Liquid Plasma Method. Journal of Power and Energy Engineering, 3, 28-35. http://dx.doi.org/10.4236/ipee.2015.38004 


\section{Introduction}

Research has been conducted into feasibility of creating saccharides from biomass sources such as grass or wood and then breaking them down and converting them into chemical products [1]-[4] or biofuels [5]-[7] in order to move away from the use of fossil fuels, such as petroleum. Cellulose, which is found in these types of nonedible biomass materials, is the most common organic compound in nature. However, because it is a highly stable compound that includes the glycosidic bond, it is difficult to decompose [8]-[11]. A process using an enzyme called cellulase is most commonly used for its decomposition [12] [13]. However, it is really the energy from hydrogen that is expected to be the ultimate energy source to solve environmental and natural resource problems [14]-[16]. While there are many issues yet to be resolved, such as methods for storing and transporting hydrogen [17] [18], it exists in wide variety of raw as well as discarded materials, so the establishment of an effective recovery system is greatly desirable. If the natural hydrogen containing compound cellulose, which exists in abundance on our planet, could be used directly to create chemical-based products such as plastic or hydrogen, or if the byproducts could be used to simultaneously create value-added chemical products, such as nano-tech materials, or combustible gases, a transition could be made aimed at changing the reliance of making items from petroleum derivatives to one that is sustainable and more ecologically sound.

One effective method of treating waste materials is using a highly active energy field of plasma [19]-[21]. Recent papers have reported on the "in-liquid plasma method" in which gas bubbles are formed in liquids under high pressure, creating a chemical reaction that reaches $3500 \mathrm{~K}$ [22] [23]. This in-liquid plasma method is currently being widely used. This development enables liquids to be directly broken down by plasma, making it possible to decompose harmful substances without a catalyst [24] [25].

In this study, the cellulose conversion into fuel gas by plasma decomposition was performed using in-liquid plasma on water to which cellulose and glucose. A constituent monosaccharide of cellulose was added. The gases generated were investigated to identify the decomposition process. Artificial breakdown technologies for non-edible biomass will be presented in this experiment.

\section{Decomposition of Saccharides Using a Batch-Type Breakdown Device}

Figure 1 depicts the schematic of the apparatus used in this study, which comprises a $27.12 \mathrm{MHz}$ high-frequency (HF) power source, matching box, reactor vessel and aspirator. As a visual window, a quartz glass container with an interior diameter of $55 \mathrm{~mm}$, an exterior diameter of $60 \mathrm{~mm}$ and a height of $85 \mathrm{~mm}$ was used in the reactor

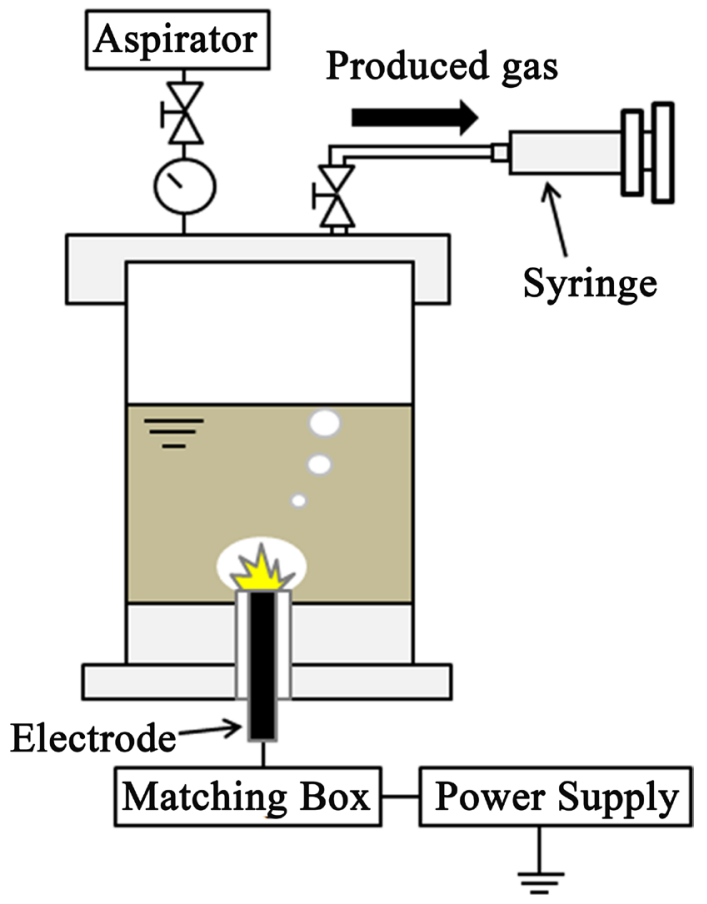

Figure 1. Batch-type plasma breakdown device. 
vessel. A copper rod $3 \mathrm{~mm}$ in diameter was used as the electrode. The side surface of the electrode was covered with heat-resistant glass in order to reduce the contact surface between the electrode and the liquid. This prevents heat transfer from the electrode to the liquid, and by covering the dielectric body, which allows the HF field to be concentrated at the tip of the electrode [26] [27].

Before the start of the experiment, the gas discharge valve is closed and an aspirator is used to create negative pressure (0.01 - $0.02 \mathrm{MPa}$ ) inside the test reactor. In this state, the power output of the HF wave power source is increased while adjusting the impedance with the matching box resulting in plasma being generated in the liquid. The valve on the aspirator side is then closed and as the plasma is maintained in a stable condition, gases are generated which fill the reactor vessel and return it to atmospheric pressure. After atmospheric pressure has been reached, the exhaust valve is opened and the generated gas mixture is extracted.

Gas chromatography (GC) is used to analyze the components of the gas mixture. The gas production rate is calculated based on the time needed for obtaining the volume of a $50 \mathrm{ml}$ syringe. The concentration of the glucose $\left(\mathrm{C}_{6} \mathrm{H}_{12} \mathrm{O}_{6}\right)$ and cellulose (Wako Pure Chemical Industries, Ltd., $38 \mu \mathrm{m}$ powder) is changed and further analysis experiments are conducted. The amount of liquid was fixed at $120 \mathrm{~g}$ and the input energy was $150 \mathrm{~W}$ at atmospheric pressure.

\section{Analysis of Generated Gas Mixture}

The relationship between the concentration of the glucose and the gas mixture generated is shown in Figure 2. At the entire of concentrations, the glucose is completely dissolved in water. Figure 2(a) shows the volume of gases analyzed by GC, which is the amount of hydrogen gas in the generated gas mixture was $52 \%-68 \%$. Due to the presence of oxygen, $\mathrm{CO}$ and $\mathrm{CO}_{2}$ gases are also generated, while hydrogen is the main gas generated by the plasma breakdown, and the flammable gas, $\mathrm{CH}_{4}$, was also produced. Gas produced in plasma decomposition of clathrate hydrate also has similar gas contents [15] [28]. Besides, Figure 2(b) shows an increase in the concentration, which brings about an increase in $\mathrm{H}_{2}, \mathrm{CO}$ and $\mathrm{CO}_{2}$ at concentrations of $5 \mathrm{wt} \%$ or less. In contrast, the amount of $\mathrm{O}_{2}$ generated decreases. At $10 \mathrm{wt} \%$, the generated amount of $\mathrm{H}_{2}$ gas stabilized.

On the contrary, the cellulose shown in Figure 3 is insoluble, but two preparations are possible depending on the amount added. At concentrations of $27 \mathrm{wt} \%$ and below, the cellulose is distributed in a liquid form while at $30 \mathrm{wt} \%$ or more, the cellulose is in a powder form in the water as shown. In addition, as the concentration of the cellulose increases, the relative amount of water decreases, so the diameter of the powder grains becomes smaller.

As shown in Figure 4, up to a concentration of $5 \mathrm{wt} \%$, the amount of $\mathrm{H}_{2}$ generated decreases as the concentration in the liquid state increases, but at $5 \mathrm{wt} \%$ or more, this changes to an increase. From $10 \mathrm{wt} \%$ to $20 \mathrm{wt} \%$, the generated $\mathrm{H}_{2}$ settles into a stable value. At $30 \mathrm{wt} \%$, the amount of each gas generated once again decreases. Then, at $40 \mathrm{wt} \%$ or more there is a change and a significant increase in gas production rate. The cellulose grains containing water at the reduced concentration of $30 \mathrm{wt} \%$ are pushed away from the region where plasma is generated by the high pressure it creates and because of the contact resistance, these larger diameter grains do not return to their original positions. Hence, air gaps form in the region of plasma generation and the plasma cannot reach the cellulose grains containing water.

Under the concentration of $40 \mathrm{wt} \%$ and above, even if the cellulose grains are pushed away by the pressure of the plasma, since the grains have smaller diameters there is less contact resistance, so even though some are pushed away, they circulate in the solution and some will sink back into the plasma region. The cellulose that returns is then directly decomposed by the plasma. By the reason of this, the gas production rate increases.

In addition, there was an increase of not only $\mathrm{H}_{2}, \mathrm{CO}, \mathrm{CO}_{2}$ in the decomposition of the cellulose, but also of ethylene and acetylene, which were not detected in the glucose decomposition. At $50 \mathrm{wt} \%$, the $\mathrm{H}_{2}$ decreases and amounts of $\mathrm{CO}, \mathrm{CO}_{2}$ and $\mathrm{CH}_{4}$ become greater than the volume of $\mathrm{H}_{2}$. This could be due to the cellulose being directly broken down by the heat of the plasma.

The $0 \mathrm{wt} \%$ in Figure 2 shows the result of plasma decomposition of pure water. In comparison, the glucose solution can generate up to approximately 1.5 times more hydrogen. In the case of cellulose in a liquid state, with the exception of the $27 \mathrm{wt} \%$, all concentrations generated hydrogen that were below the value for thermal decomposition of water. With the intent of investigating the reaction mechanism in detail, the number of hydrogen, oxygen and carbon atoms making up the gas were calculated using the generation rate.

The change in the number of generated gas atoms in relation to the concentration for the glucose solution showed the same tendencies for each concentration (see Figure 5(a)). The generation of carbon atoms rises 
nearly proportionally to the concentration since carbon atoms will only be generated due to the glucose reaction, at low concentrations, but levels off at high concentrations. On the other hand, there were nearly no carbon atoms generated at $5 \mathrm{wt} \%$ or lower in the case of the cellulose as shown in Figure 5(b), and the number of hydrogen and oxygen atoms generated fell as the concentration increased. This is because cellulose distributed through the liquid interferes with the reaction of the water and at low concentrations, only the water reacts. At concentrations of $10 \mathrm{wt} \%$ and above, not only the water, but also the cellulose reacts. In the concentrations of 40

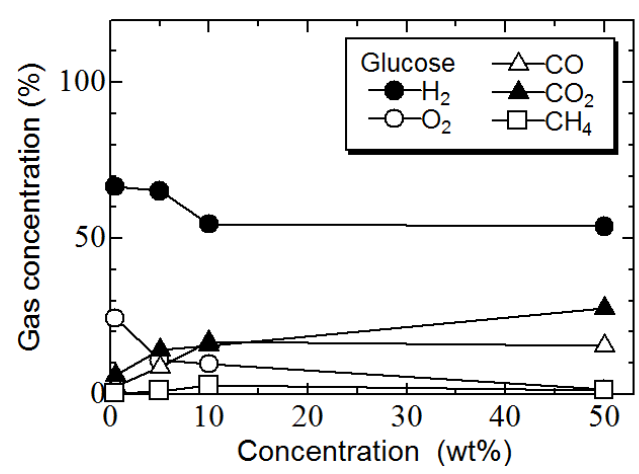

(a)

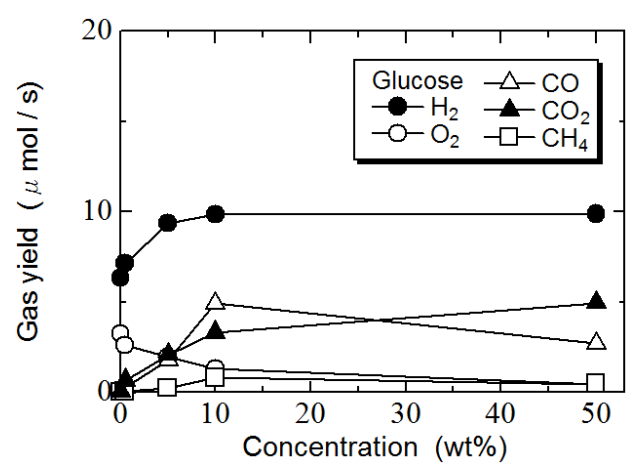

(b)

Figure 2. Plasma decomposition of glucose: (a) Volume of gas contents, (b) Gas production rate.
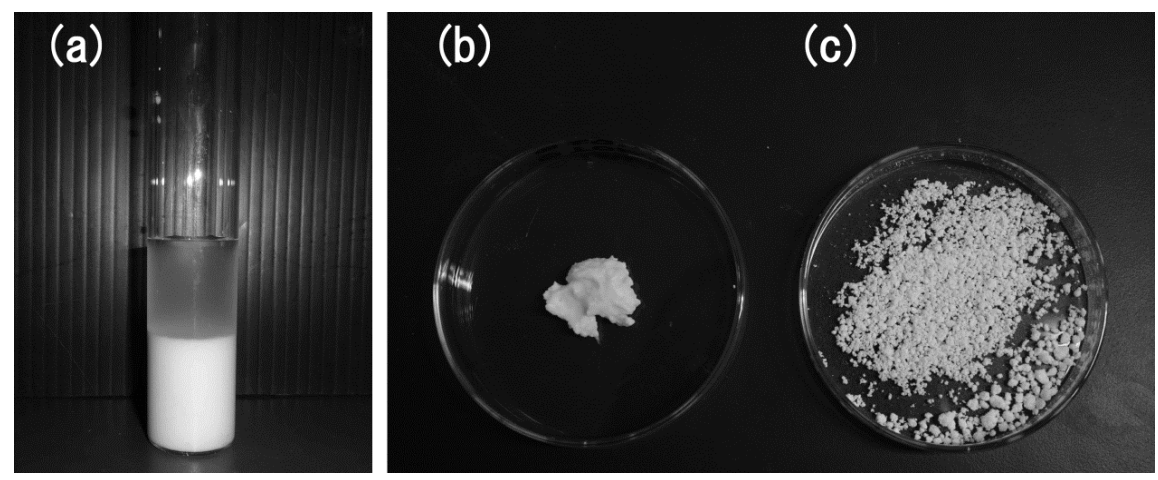

Figure 3. Images of cellulose soaked in water: (a) $10 \mathrm{wt} \%$, (b) $30 \mathrm{wt} \%$, (c) $50 \mathrm{wt} \%$.

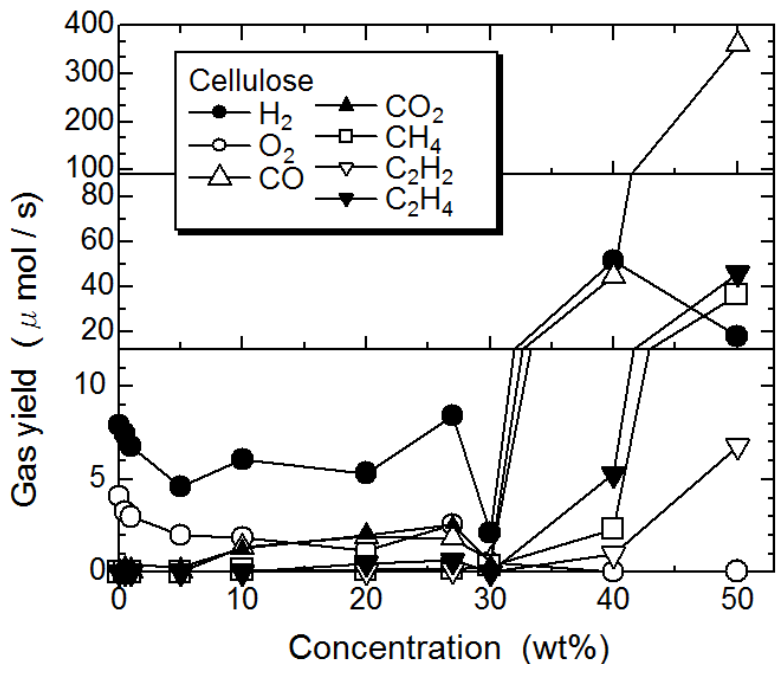

Figure 4. Gas production rate obtained by plasma decomposition of cellulose. The amount of gas generated is greatly changed by the concentration. 
wt $\%$ or above, the ratio of $\mathrm{C}$ and $\mathrm{O}$ in relation to $\mathrm{H}$ in the gas mixture increases, intensifying the decomposition reaction by the plasma. Additionally, in concentrations of $40 \mathrm{wt} \%$ or less, the generation of $\mathrm{H}, \mathrm{O}, \mathrm{C}$ is nearly the same, but after the concentration reaches $50 \mathrm{wt} \%$, the amount of $\mathrm{O}$, and $\mathrm{C}$ generated become greater than $\mathrm{H}$.

A related finding was that the reaction of glucose and cellulose in the liquid state is not due to a direct decomposition reaction by the plasma. Because of the In-liquid plasma is generated in the air bubbles created by the heat of the plasma evaporating the surrounding liquid. Thus, the glucose and cellulose cannot enter into these air bubbles due to its nonvolatile property.

Based on analyses of the values of plasma in pure water performed previously, the evaporated water in the air bubbles is decomposed by the plasma and the large volume of $\mathrm{OH}$ radicals that have been created are dispersed into the water [29] [30]. In addition, experiments have shown an increase in the concentration of hydrogen peroxide, which is thought to be formed from the $\mathrm{OH}$ radicals in the pure water [31]. $\mathrm{OH}$ radicals have a strong oxidizing property that indirectly breaks down the glucose and cellulose.

Spectrometry measurements were performed in order to investigate the types of radical formations in the plasma. Figure 6(a) shows the emission spectrum of pure water. $\mathrm{H}_{\alpha}(656 \mathrm{~nm}), \mathrm{H}_{\beta}(486 \mathrm{~nm}) \mathrm{OH}, \mathrm{O}(777 \mathrm{~nm})$ and $\mathrm{O}(845 \mathrm{~nm})$ are detected due to the presence of hydrogen and oxygen radicals resulting from the decomposition of water. Figure 6(b) shows the plasma emission spectrum for a glucose solution with a concentration of 50 wt\%. Strong emission spectrums could be seen: $486 \mathrm{~nm}$ for $\mathrm{H}_{\beta}$, 500 to $600 \mathrm{~nm}$ for $\mathrm{Cu}, 656 \mathrm{~nm}$ for $\mathrm{H}_{\alpha}$ and 777 to $824 \mathrm{~nm}$ for $\mathrm{O} . \mathrm{Cu}$ and $\mathrm{Na}(589 \mathrm{~nm})$ are the materials used for the electrode and the heat-resisting glass. When the glucose and cellulose are directly broken down by the plasma, the expected spectrums of CO (250 to $400 \mathrm{~nm}$ ) and $\mathrm{C}_{2}(\approx 516 \mathrm{~nm})$ could be confirmed. However, the spectrum from the $\mathrm{OH}$ radicals seen at $309 \mathrm{~nm}$ during spectrometry of plasma in pure water was difficult to confirm. This is because the liquid after the plasma has been created has the ability to absorb ultraviolet light [32] [33].

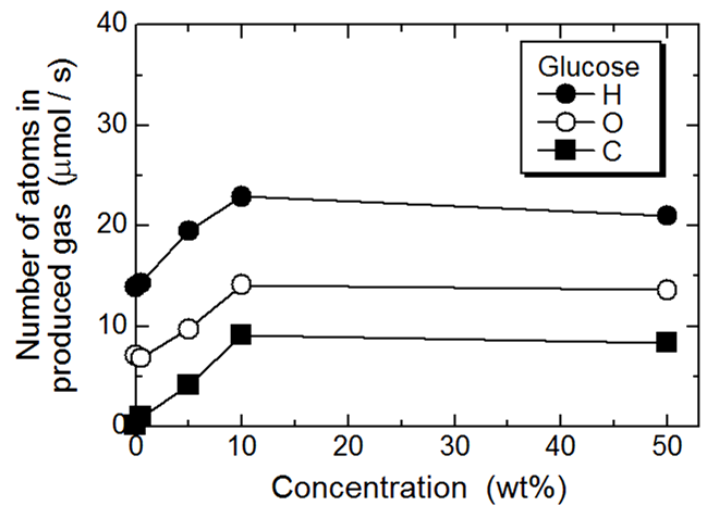

(a)

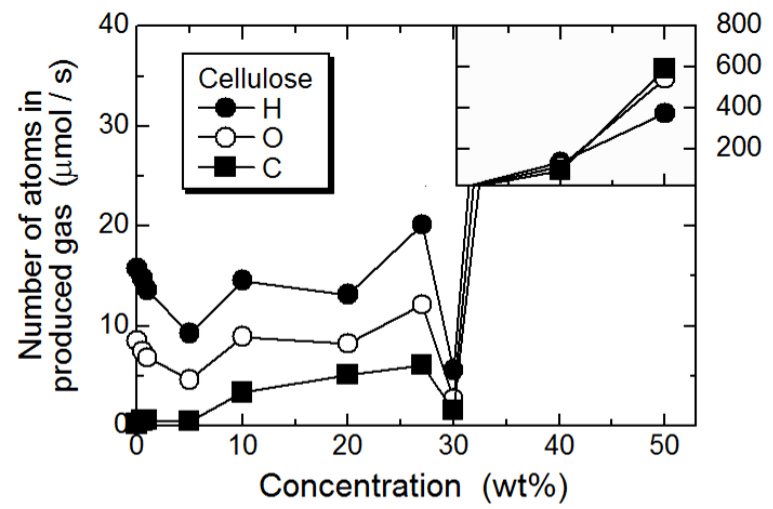

(b)

Figure 5. Number of hydrogen, oxygen and carbon atoms in the generated gas: (a) glucose, (b) cellulose.

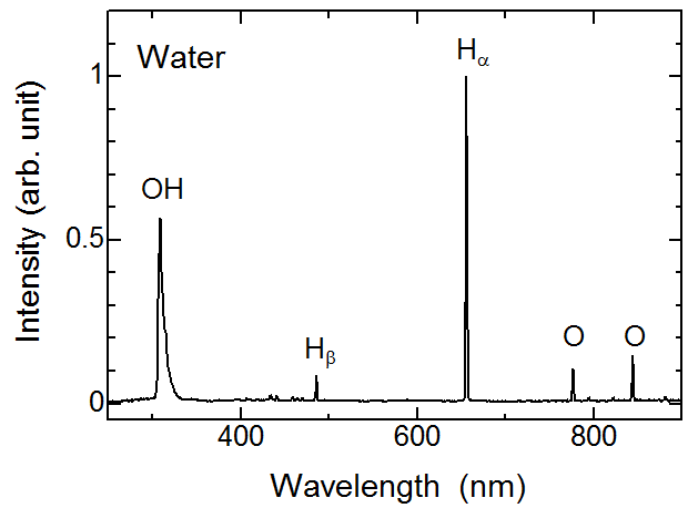

(a)

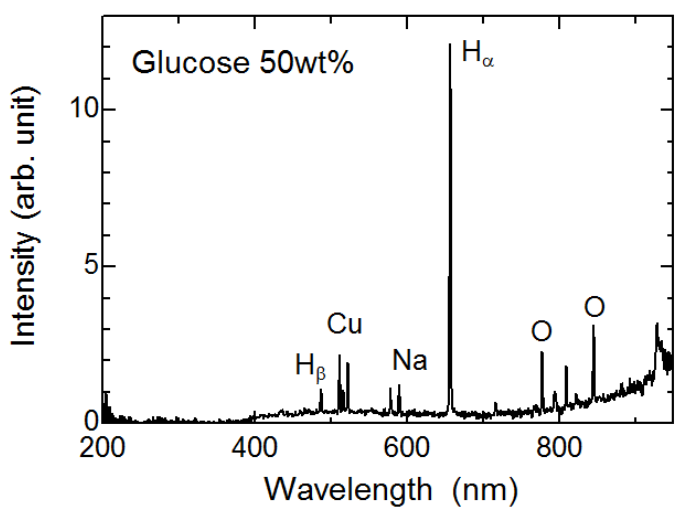

(b)

Figure 6. Plasma spectrometry measurements: (a) pure water, (b) glucose concentration at 50\%. 


\section{Decomposition of Saccharides Using a Funnel Shaped Device for Breakdown}

The problem of the cellulose not being able to enter into the plasma region was found using the experimental apparatus in the previous section. Therefore, as shown in Figure 7, the testing apparatus was improved by adding a taper to the bottom of the reactor vessel to form a funnel shape that makes it easier for the cellulose to accumulate at the bottom. The reactor vessel is funnel shaped and made of Pyrex glass. The liquid reservoir section has an inner diameter of $22 \mathrm{~mm}$ and an outer diameter of $25 \mathrm{~mm}$. The section where the electrode is inserted has an inner diameter of $4 \mathrm{~mm}$ and an outer diameter of $6 \mathrm{~mm}$. It is expected that the slope of the funnel will enable any cellulose that has settled to the bottom of the liquid reservoir to be efficiently broken down. A $3 \mathrm{~mm}$ diameter rod is used for the electrode. The top of the container is sealed with a silicone plug, making the container airtight. Before the start of the experiment, the gas discharge valve was closed and an aspirator was used to create negative pressure inside the vessel. After the pressure inside the device returned to atmospheric pressure, the gas was collected using the same procedure described in the previous section. The reaction liquid was a dissolved glucose solution in which powdered cellulose was dispersed.

Figure 8 shows the relationship between the concentrations of the gases generated for glucose and cellulose. As with the batch-type experiment, when the glucose concentration was $5 \mathrm{wt} \%$ or below, the amounts of $\mathrm{H}_{2}$, $\mathrm{CO}$, and $\mathrm{CO}_{2}$ generated increased as the concentration increased while the amount of $\mathrm{O}_{2}$ gas was reduced. In concentrations of $10 \mathrm{wt} \%$ and above, the amount of $\mathrm{H}_{2}$ gas generated stabilized.

The amount of hydrogen generated was approximately twice the amount generated by the batch type device. In addition, the highest speed of hydrogen generation for cellulose in the funnel type device was approximately three times the highest value for the batch type in the liquid state. However, when compared to the concentration of 40 wt\% shown in Figure 2, the amount of $\mathrm{CO}$ and $\mathrm{CO}_{2}$ gas attained was smaller and direct decomposition of the cellulose by the plasma did not occur. How to introduce nonvolatile materials or fixed shaped particles into the plasma will be a topic for future research.

\section{Conclusion}

In this research, experiments for in-liquid plasma breakdown of glucose and cellulose were conducted and the components of the generated gas mixture were analyzed and the gas production rate was measured. Using plasma decomposition, a dissolved glucose-water solution is proposed, in which cellulose was dispersed to generate

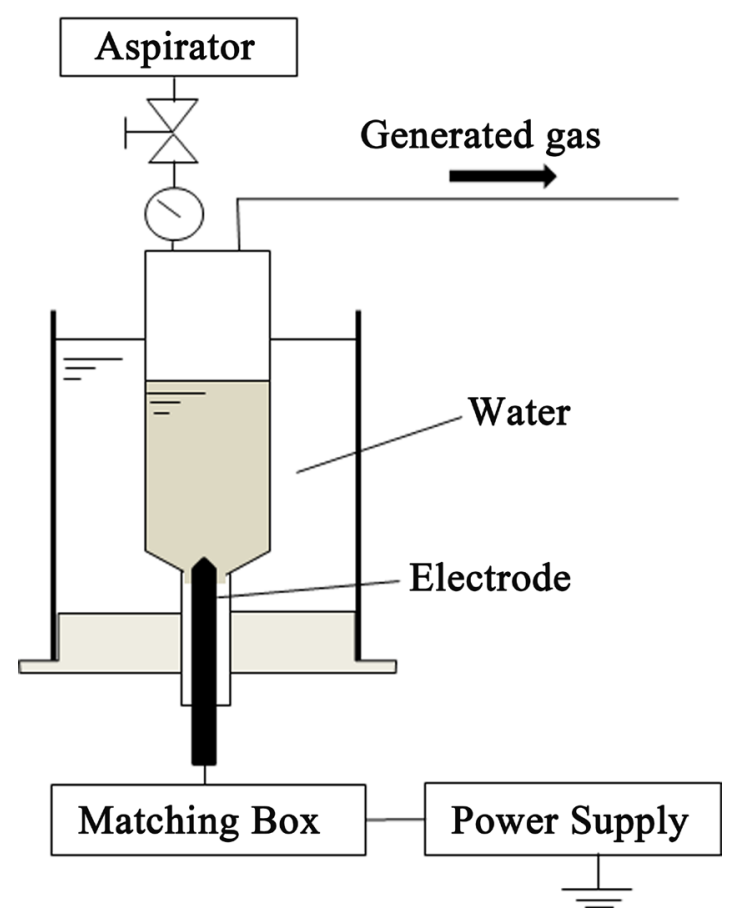

Figure 7. Plasma breakdown device using a funnel-shaped reactor. 


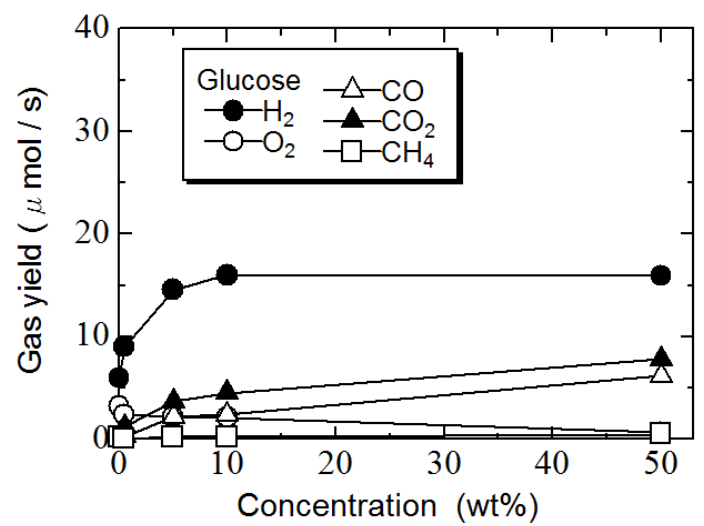

(a)

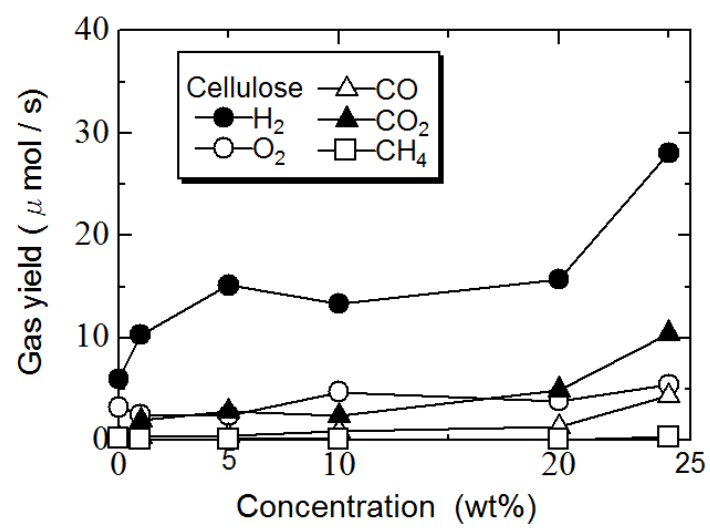

(b)

Figure 8. Plasma decomposition experiments using saccharides in a funnel-shaped reactor: (a) glucose, (b) cellulose.

a gas mixture that contains $50 \%-66 \%$ of hydrogen gas. With the batch-type device, the cellulose became a powder at concentrations of $30 \mathrm{wt} \%$ and above. At concentrations $40 \mathrm{wt} \%$ and above, the generation of gas significantly increased because the powder entered directly into the plasma and the cellulose was directly broken down by thermal decomposition in the plasma. When the glucose-water solution or a solution with dispersed cellulose had concentrations of $27 \mathrm{wt} \%$ or less, the saccharides were not directly decomposed by the heat of the plasma, but rather were decomposed indirectly by active type radicals created by the plasma. With the funnelshaped device, the generation speed of the hydrogen gas was greater than that of the batch-type device, but in this case as well, the direct heat from the plasma had little effect on the decomposition.

\section{References}

[1] De Souza, R.L., Yu, H., Rataboul, F. and Essayem, N. (2012) 5-Hydroxymethylfurfural (5-HMF) Production from Hexoses: Limits of Heterogeneous Catalysis in Hydrothermal Conditions and Potential of Concentrated Aqueous Organic Acids as Reactive Solvent System. Challenges, 3, 212-232. http://dx.doi.org/10.3390/challe3020212

[2] Lai, L. and Zhang, Y. (2011) The Production of 5-Hydroxymethylfurfural from Fructose in Isopropyl Alcohol: A Green and Efficient System. ChemSusChem, 4, 1745-1748. http://dx.doi.org/10.1002/cssc.201100489

[3] Tong, X., Ma, Y. and Li, Y. (2010) Biomass into Chemicals: Conversion of Sugars to Furan Derivatives by Catalytic Processes. Applied Catalysis A, 385, 1-13. http://dx.doi.org/10.1016/j.apcata.2010.06.049

[4] Kazi, F.K., Patel, A.D., Serrano-Ruiz, J.C., Dumesic, J.A. and Anex, R.P. (2011) Techno-Economic Analysis of Dimethylfuran (DMF) and Hydroxymethylfurfural (HMF) Production from Pure Fructose in Catalytic Processes. Chemical Engineering Journal, 169, 329-338. http://dx.doi.org/10.1016/j.cej.2011.03.018

[5] Kawashima, A., Matsubara, K. and Honda, K. (2008) Development of Heterogeneous Base Catalysts for Biodiesel Production. Bioresource Technology, 99, 3439-3443. http://dx.doi.org/10.1016/j.biortech.2007.08.009

[6] Kawashima, A., Matsubara, K. and Honda, K. (2009) Acceleration of Catalytic Activity of Calcium Oxide for Biodiesel Production. Bioresource Technology, 100, 696-700. http://dx.doi.org/10.1016/j.biortech.2008.06.049

[7] Brethauer, S. and Wyman, C.E. (2010) Continuous Hydrolysis and Fermentation for Cellulosic Ethanol Production. Bioresource Technology, 101, 4862-4874. http://dx.doi.org/10.1016/j.biortech.2009.11.009

[8] Chundawat, S.P., Bellesia, G., Uppugundla, N., da Costa Sousa, L., Gao, D., Cheh, A.M., Agarwal, U.P., Bianchetti, C.M., Phillips Jr., G.N., Langan, P., Balan, V., Gnanakaran, S. and Dale, B.E. (2011) Restructuring the Crystalline Cellulose Hydrogen Bond Network Enhances Its Depolymerization Rate. Journal of the American Chemical Society, 133, 11163-11174. http://dx.doi.org/10.1021/ja2011115

[9] Nishiyama, Y., Lngan, P. and Chanzy, H. (2002) Crystal Structure and Hydrogen-Bonding System in Cellulose I $\beta$ from Synchrotron X-Ray and Neutron Fiber Diffraction. Journal of the American Chemical Society, 124, 9074-9082. http://dx.doi.org/10.1021/ja0257319

[10] Xiang, Q., Lee, Y.Y., Pettersson, P.O. and Torget, R.W. (2003) Heterogeneous Aspects of Acid Hydrolysis of $\alpha$-Cellulose. Applied Biochemistry and Biotechnology, 107, 505-574. http://dx.doi.org/10.1385/ABAB:107:1-3:505

[11] Sakaki, T., Shibata, M., Miki, T., Hirosue, H. and Hayashi, N. (1996) Decomposition of Cellulose in Near-Critical Water and Fermentability of the Products. Energy \& Fuels, 10, 684-688. http://dx.doi.org/10.1021/ef950160+ 
[12] Yang, B., Dai, Z.Y., Ding, S.Y. and Wyman, C.E. (2011) Enzymatic Hydrolysis of Cellulosic Biomass. Biofuels, 2, 421-450. http://dx.doi.org/10.4155/bfs.11.116

[13] Horn, S.J., Vaaje-Kolsad, G., Westereng, B. and Eijsink, V.G.H. (2012) Novel Enzymes for the Degradation of Cellulose. Biotechnology for Biofuels, 5, 45. http://dx.doi.org/10.1186/1754-6834-5-45

[14] Lalaurette, E., Thammannagowda, S., Mohagheghi, A., Maness, P.C. and Logan, B.E. (2009) Hydrogen Production from Cellulose in a Two-Stage Process Combining Fermentation and Electrohydrogenesis. International Journal of Hydrogen Energy, 34, 6201-6210. http://dx.doi.org/10.1016/j.ijhydene.2009.05.112

[15] Putra, A.E.E., Nomura, S., Mukasa, S. and Toyota, H. (2012) Hydrogen Production by Radio Frequency Plasma Stimulation in Methane Hydrate at Atmospheric Pressure. International Journal of Hydrogen Energy, 37, 16000-16005. http://dx.doi.org/10.1016/j.ijhydene.2012.07.099

[16] Abbas, F.H. and Wan Daud, W.M.A. (2010) Hydrogen Production by Methane Decomposition: A Review. International Journal of Hydrogen Energy, 35, 1160-1190. http://dx.doi.org/10.1016/j.ijhydene.2009.11.036

[17] Tozzini, V. and Pellegrini, V. (2013) Prospects for Hydrogen Storage in Graphene. Physical Chemistry Chemical Physics, 15, 80-89. http://dx.doi.org/10.1039/C2CP42538F

[18] Ma, T., Isobe, S., Morita, E., Wang, Y., Hashimoto, N., Ohnuki, S., Kimura, T., Ichikawa, T. and Kojima, Y. (2011) Correlation between Kinetics and Chemical Bonding State of Catalyst Surface in Catalyzed Magnesium Hydride. International Journal of Hydrogen Energy, 36, 12319-12323. http://dx.doi.org/10.1016/j.ijhydene.2011.07.011

[19] Heberlein, J. and Murphy, A.B. (2008) Thermal Plasma Waste Treatment. Journal physics D, 41, Article ID: 053001.

[20] Choi, S., Park, D.W. and Watanabe, T. (2012) Thermal Plasma Decomposition of Fluorinated Greenhouse Gases. Nuclear Engineering and Technology, 44, 21-32. http://dx.doi.org/10.5516/NET.77.2012.003

[21] Sakano, M., Tanaka, M. and Watanabe, T. (2001) Application of Radio-Frequency Thermal Plasmas to Treatment of Fly Ash. Thin Solid Films, 386, 189-194. http://dx.doi.org/10.1016/S0040-6090(00)01641-2

[22] Nomura, S., Mukasa, S., Toyota, H., Miyake, H., Yamashita, H. and Maehara, T. (2011) Characteristics of In-Liquid Plasma in Water under Higher Pressure Than Atmospheric Pressure. Plasma Sources Science and Technology, 20, Article ID: 034012. http://dx.doi.org/10.1088/0963-0252/20/3/034012

[23] Maehara, T., Miyamoto, I., Kurokawa, K., Hashimoto, Y., Iwamae, A., Kuramoto, M., Yamashita, H., Mukasa, S., Toyota, H., Nomura, S. and Kwashima, A. (2008) Degradation of Methylene Blue by RF plasma in Water. Plasma Chemistry and Plasma Processing, 28, 467-482. http://dx.doi.org/10.1007/s11090-008-9142-2

[24] Nomura, S., Toyota, H., Mukasa, S., Yamashita, H., Maehara, T. and Kawashima, A. (2009) Production of Hydrogen in a Conventional Microwave Oven. Journal of Applied Physics, 106, Article ID: 073306. http://dx.doi.org/10.1063/1.3236575

[25] Kurihara, H. and Yajima, T. (2007) Decomposition of Toluene by Liquid-phase Atmospheric-Pressure Microwave Plasma Generated Using Carbon Felt Pieces Impregnated with NaCl. Chemistry Letters, 36, 870-871. http://dx.doi.org/10.1246/cl.2007.870

[26] Hattori, Y., Mukasa, S., Nomura, S. and Toyota, H. (2010) Optimization and Analysis of Shape of Coaxial Electrode for Microwave Plasma in Water. Journal of Applied Physics, 107, Article ID: 063305. http://dx.doi.org/10.1063/1.3319616

[27] Hattori, Y., Mukasa, S., Toyota, H. and Nomura, S. (2013) Electrical Breakdown of Microwave Plasma in Water. Current Applied Physics, 13, 1050-1054. http://dx.doi.org/10.1016/j.cap.2013.02.012

[28] Nomura, S., Putra, A.E.E., Mukasa, S., Yamashita, H. and Toyota, H. (2011) Plasma Decomposition of Clathrate Hydrates by 2.45GHz Microwave Irradiation at Atmospheric Pressure. Applied Physics Express, 4, Article ID: 066201. http://dx.doi.org/10.1143/APEX.4.066201

[29] Mukasa, S., Nomura, S., Toyota, H., Maehara, T., Abe, F. and Kawashima, A. (2009) Temperature Distributions of Radio-Frequency Plasma in Water by Spectroscopic Analysis. Journal of Applied Physics, 106, Article ID: 113302. http://dx.doi.org/10.1063/1.3264671

[30] Mukasa, S., Nomura, S., Toyota, H., Maehara, T. and Yamashita, H. (2011) Internal Conditions of a Bubble Containing Radio-Frequency Plasma in Water. Plasma Sources Science and Technology, 20, Article ID: 034020. http://dx.doi.org/10.1088/0963-0252/20/3/034020

[31] Yang, Y., Cho, Y.I. and Fridman, A. (2012) Plasma Discharge in Liquid: Water Treatment and Applications. CRC Press, Boca Raton, 102.

[32] Sato, M. (2009) Degradation of Organic Contaminants in Water by Plasma. International Journal of Plasma Environmental Science and Technology, 3, 8-14.

[33] Maehara, T., Nishiyama, K., Onishi, S., Mukasa, S., Toyota, H., Kuramoto, M., Nomura, S. and Kawashima, A. (2010) Degradation of Methylene Blue by Radio Frequency Plasmas in Water under Ultraviolet Irradiation. Journal of Hazardous Materials, 74, 473-476. http://dx.doi.org/10.1016/j.jhazmat.2009.09.076 